\title{
Main Points of Digital Agency Business Processes Management: Foodtech Sector Case
}

\author{
Elena Omelyanenko ${ }^{1 *}$, Teofilo Tirto $^{2}$, Dmitry Volodinn $^{2}$, Vitaliy Omelyanenko ${ }^{1,3}$, and Galina \\ Kovtun $^{1}$ \\ ${ }^{1}$ Department of Business Economics and Administration, Sumy State Pedagogical University named \\ after A. S. Makarenka, 40002, Romenska str., 87, Sumy, Ukraine \\ ${ }^{2}$ R\&D Department, FARADI SRL, Italy \\ ${ }^{3}$ Teadmus OÜ, Estonia
}

\begin{abstract}
The research deals with the analytics of the features of business processes of a digital agency and the identification of promising aspects of digital marketing as a tool for B2B interaction in the Foodtech market. It is noted that the primary trend of the Foodtech sector deals with digital transformation. From the strategic point of view of creating a business model, it is necessary to understand that digital transformation involves the installation of modern hardware or software and fundamental changes in approaches to management, corporate culture, and communications. To increase the efficiency of the digital agency's business model, the authors propose to consider digital marketing. The analysis of the effectiveness of the business model of the digital agency allowed us to identify the most problematic and, at the same time, promising components of the business model. Based on generalized approaches to business model management in the case of a digital agency in the design of relevant services, it is proposed to consider maximizing the speed and efficiency of business model transformation and minimizing the uncertainty of further digital service development based on customer relationship management. Keywords: Foodtech sector, digital agency, business processes management, digital transformation.
\end{abstract}

\section{Introduction}

The analysis of the practical implementation of digital marketing allowed us to conclude that in rapid digital transformations, active market participants are digital agencies that provide a wide range of services to solve creative and technical problems for various services in the Internet space.

Digital agencies play a unique role in the implementation of digital marketing functions because, in contrast to media or marketing agencies that provide platforms for advertising, offer information and analytical services, which can determine the specifics of business models in the digital sphere:

- standard services (site creation, media and contextual promotion, design, site

* Corresponding author: elnikkrasnaya@gmail.com 
development);

- development of a comprehensive strategy for the development of the enterprise in the digital environment (examination and promotion);

- work with online communities (groups and pages in social networks, blogs, forums, specialized sites);

- organization of event events, competitions (strategy, creative, implementation, performance analysis) in combinations of online/offline promotion;

- consumer transition from online to offline and back (promotions, etc.);

- experimental marketing, QR codes, geolocation services, RFD, WOW-calls, augmented reality, etc.

Based on the considered range of digital agency services, the primary task of digital marketing is to identify and attract both traffic (for customers) and potential customers (for the customer). This can be done by reviewing organizational capabilities (strategy, culture, change management, innovation management and customer path maps).

In our study, we will analyze the features of the business processes of a digital agency and identify promising aspects of the use of elements of digital marketing as a tool for B2B interaction in the Foodtech market.

\section{Foodtech sector business processes management trends}

The primary trend of the Foodtech sector deals with digital transformation. From the strategic point of view of creating a business model, it is necessary to understand that digital transformation involves the installation of modern hardware or software and fundamental changes in approaches to management, corporate culture, and communications. As a result, productivity and customer satisfaction increase, and the company acquires a reputation for being progressive and modern.

Digitalization of business processes is relevant not only at the level of individual enterprises. In current conditions, some industries choose this development path as the only way to meet the dynamic market conditions. Not inferior to the above sectors and the restaurant business, the integration of digital technologies already forms a whole segment Foodtech. In the foreign market, we can identify the following main areas of Foodtech:

- delivery of food from restaurants and cafes through online arrangements;

- delivery of food through online arrangements;

- Possibility to pre-order meals up to a specific time / take away food;

- availability of a large number of services with a broad base of restaurants and the ability to order meals online.

As a result, the digitalization of the restaurant business model takes place in two directions: communication with the customer goes online, and the large-scale introduction of automation reduces the number of staff involved in service and management.

According to the study, one of the stable trends in recent years is the growing popularity of loyalty programs. Special offers and marketing promotions are now available in almost all restaurants, and customers before visiting the institution, customers at least browse the institution's site, the public on social networks, and read reviews. In addition, in the face of growing competition, the classic bonus programs are being replaced by more advanced promotions, programs with elements of gamification, etc.

Loyalty programs are also digitally converting en masse. Instead of plastic cards, mobile applications combine a bonus system, the ability to book tables, information systems, special offers, personal recommendations, food diaries, and feedback tools.

In contrast to the foreign restaurant market, where digitalization has now reached a high level (the share of penetration of online service in the food segment in the US is $3 \%$, in the UK 7\%), Foodtech in Ukraine is just beginning to be implemented - the share of online 
services is no more a few per cent. According to analysts, the restaurant business in 2021 shows some growth and is actively developing the field of e-commerce.

These factors indicate the need for active implementation and development of Foodtech because the catering market is waiting for a change shortly. From the practical point of view of Foodtech implementation, the restaurant business's main task will be to make ordering as easy as possible and innovate to make ordering possible in one or two clicks.

It is necessary to analyze the market and the target audience's demands to solve this problem. Current trends in the e-commerce market and online orders dictate the need to use advanced analytics about the target audience.

As a rule, restaurants do not have such statistics and, accordingly, do not have flexible and convenient tools for proactive management of the business model, thus sales, promotion, and revenue growth.

It is necessary to have complete information about the target consumer and to personalize the data about him as much as possible to build a business model and provide quality service. This will allow us to effectively use advertising channels and regulate workflows in the right direction.

In these conditions, implementing the system (system elements), Big Data allows you to get advanced analytics for users in any field, which opens vast opportunities for business owners. Ability to personalize, improve the quality of services, change and expand the range can significantly improve the quality of service or service. With the development of ecommerce and the Foodtech market, advanced analytics will become increasingly necessary in business.

Gartner experts believe that the success of digitalization depends not so much on modern technology as on the availability of built production processes and systems. Skills, initiatives and business models are 15 times more important for success in digitalization than disparately implemented technologies [mosto].

The business intelligence system helps reduce costs through its optimization. You can accumulate all the data on one platform and make decisions based on the real situation in real-time. In other words, automation of analytics allows us to manage the enterprise most effectively.

From this point of view, the main task of the restaurant management system is to manage information flows, and business intelligence systems allow us to store and process large amounts of data.

Break-even investment in the business process management system arises with the beginning of a systematic analysis of the business processes of the enterprise in order to strategically improve them. Therefore, developing a model of analytical indicators of business processes is one of the most critical and complex tasks of business intelligence development. According to the author of the study [1], levels of decomposition have the following purpose in business intelligence:

- strategic level "Activity" is an abstract model of planning the goal vector and determining the priorities of business system development;

- tactical level "Processes" (business functions) is designed to ensure the balance of the system based on functional budgets in the development process, as well as for timely response to critical changes in the external and internal environment of the enterprise and adaptation to them;

- the level of "Operation" involves the actual management based on the strategic objective function and tactical budget constraints, measured and improved parameters of specific actions.

Thus, the preliminary analysis of business processes in the introduction of digital technologies in the restaurant business, in addition to potential conveniences for customers, opens up many new opportunities for the business itself. Among them, we can note the 
optimization of the kitchen and the ability to plan loading, revenue growth by reaching a new audience. In these conditions, the services and platforms of specialized business analytics allow us to bring to a new progressive level of customer service and effective marketing management.

Note that previously to enter the online market successfully, the entrepreneur had to order a specific site, create several pages (landing page) using one of the online services, buy a subscription base (at best - to collect), give a few advertising posts in social networks and understand the basics of SEO promotion. This provided a sufficient level of profit. However, in current conditions, everything is changing, and Internet technologies for business are not enough, traditional advertising only spends the budget, people's interest quickly fades, one wrong decision - and the subscriber base is already ineffective. At the same time, new digital communication channels appear with a wide range of opportunities for promotion, which leads to a change in the business model and forms the field of digital marketing.

\section{Equations and mathematics}

To increase the efficiency of the digital agency's business model, we propose to consider digital marketing. Digital marketing as an element of strategic management in building a business model can be defined by the following theses:

- a comprehensive approach to the promotion of the enterprise, its products and services in the digital environment, which also includes offline consumers using games, mobile phones and other digital means of communication;

- integration of a large number of different technologies (social, mobile, web, CRMsystems, etc.) with sales and customer service;

- ensuring constant quality two-way communication between the advertiser and the enduser of the product (service);

- the ability to combine technology and human resources, maintaining the right balance based on the needs of the target audience and the properties of the proposed product;

- phenomenal dynamics of growth and achievement of any marketing goals;

- the ability to be relevant to market requirements, evaluate and analyze the promotion results, flexibly respond to customer needs and adjust our product (service).

The analysis of the digital agency business model effectiveness allowed to identify the most problematic and at the same time promising components of the business model (Table 1).

Table 1. Components of business model with negative status.

\begin{tabular}{|c|c|c|c|c|}
\hline $\begin{array}{c}\text { Component of } \\
\text { business model }\end{array}$ & Factors & Weight & $\begin{array}{c}\text { Current } \\
\text { status }\end{array}$ & Rating \\
\hline \multirow{2}{*}{ Customer relations } & $\begin{array}{c}\text { Assistance in improving business } \\
\text { processes }\end{array}$ & 22,73 & -2 & $-45,5$ \\
\cline { 2 - 5 } & $\begin{array}{c}\text { Support of projects after their } \\
\text { implementation }\end{array}$ & 22,73 & -1 & $-22,7$ \\
\hline Sales channels & $\begin{array}{c}\text { Use of digital marketing } \\
\text { technologies }\end{array}$ & 50,00 & -1 & $-50,0$ \\
\hline Key partners & $\begin{array}{c}\text { Existence of strategic partnerships } \\
\text { (B2B) }\end{array}$ & 68,18 & -1 & $-68,2$ \\
\hline Key resources & Strategic management & 86,36 & -1 & $-86,4$ \\
\hline $\begin{array}{c}\text { Consumer } \\
\text { segments }\end{array}$ & Consumer diversification & 50,00 & -1 & $-50,0$ \\
\hline Costs structure & Investments & 100,00 & -1 & $-100,0$ \\
\hline
\end{tabular}

Based on generalized approaches to business model management in the case of a digital agency in the design of relevant services, we propose to consider maximizing the speed and 
efficiency of business model transformation and minimizing the uncertainty of further digital service development based on customer relationship management (in our case, restaurants and customers).

In traditional business models, consumers are also given importance, but in the case of a digital agency, it is necessary to create a system that meets the needs of both restaurant consumers and restaurant customers. Note that the inclusion of two groups of consumers in the service development process is traditionally limited to the initial and final phases of the project.

Note that from the standpoint of the M2 model, the primary purpose of the enterprise working in the field of digital promotion of restaurants, we can define as follows:

- ensuring interaction between project developers and the customer;

- observation and control of works, estimation of intermediate variants of services on the observance of requirements, correct performance, estimation of service and actual expenses;

- coordination of intermediate results of digital service design with the customer;

- checking the correctness of the digital service by testing it on planned and agreed with the customer test suites;

- assessment of compliance of digital service quality characteristics with the set requirements;

- discussion of the components of the digital service used in terms of assessing their capabilities and shortcomings identified in their application, as well as identifying areas for improvement or modernization of the service.

\section{Conclusion}

Thus, a digital agency is an enterprise that can provide restaurants (customers) with expert judgment and ensure the implementation of ideas in website creation, creativity, strategy, advertising and customer service. Digital agencies are not limited to creating websites. They work comprehensively to create and strengthen its name in the market and its positioning in the media using effective viral advertising.

From the point of view of creating a business model, the agency's work must not stop at the end of the project. Representatives of such an enterprise can continue to develop the project for years, promote it in the media, striving to maximize its image and customer loyalty.

\section{References}

1. D. Mogilko, Business Process Analytics. URL: https://www.businessstudio.ru/articles/article/analitika biznes_protsessov/ (2018). 126

2. M. Mosto, Digital doubles, open new opportunities for the instrument making and electronics industries. URL: https://controlengrussia.com/innovatsii/novyevozmozhnosti/ (2019)

3. Yu. Robul, I. Lytovchenko, Li Tchon, Ye. Nagornyi, O. Omelianenko, International Journal of Scientific \& Technology Research, 9, 4 (2020)

4. V.A. Omelyanenko, O.M. Omelianenko, Digital component of relationship marketing in services sector, in Proceedings of the International Scientific Conference Marketing of innovations. Innovations in marketing, December, 2020. Bielsko-Biala (2020)

5. V. O. Braslavska, N. Biloshkurska, M. Biloshkurskyi, N. Kliasen, O. Omelyanenko, International Journal of Computer Science and Network Security, 21, 9 (2021) 